ARTICLE

Received 25 Dec 2012 | Accepted 1 Jul 2013 | Published 31 Jul 2013 DOl: 10.1038/ncomms3221 OPEN

\title{
Stable platinum nanoclusters on genomic DNA-graphene oxide with a high oxygen reduction reaction activity
}

Jitendra N. Tiwari ${ }^{1}$, Krishna Nath ${ }^{2}$, Susheel Kumar ${ }^{2}$, Rajanish N. Tiwari ${ }^{3}$, K. Christian Kemp ${ }^{1}$, Nhien H. Le ${ }^{1}$, Duck Hyun Youn ${ }^{4}$, Jae Sung Lee ${ }^{5} \&$ Kwang S. Kim ${ }^{1}$

Nanosize platinum clusters with small diameters of 2-4 $\mathrm{nm}$ are known to be excellent catalysts for the oxygen reduction reaction. The inherent catalytic activity of smaller platinum clusters has not yet been reported due to a lack of preparation methods to control their size $(<2 \mathrm{~nm})$. Here we report the synthesis of platinum clusters (diameter $\leq 1.4 \mathrm{~nm}$ ) deposited on genomic double-stranded DNA-graphene oxide composites, and their high-performance electrocatalysis of the oxygen reduction reaction. The electrochemical behaviour, characterized by oxygen reduction reaction onset potential, half-wave potential, specific activity, mass activity, accelerated durability test (10,000 cycles) and cyclic voltammetry stability ( 10,000 cycles) is attributed to the strong interaction between the nanosize platinum clusters and the DNA-graphene oxide composite, which induces modulation in the electronic structure of the platinum clusters. Furthermore, we show that the platinum cluster/DNA-graphene oxide composite possesses notable environmental durability and stability, vital for high-performance fuel cells and batteries.

\footnotetext{
${ }^{1}$ Center for Superfunctional Materials, Department of Chemistry, Pohang University of Science and Technology, San 31, Hyojadong, Namgu, Pohang 790-784, Korea. ${ }^{2}$ Division of Molecular and Life Sciences, Pohang University of Science and Technology, Pohang 790-784, Korea. ${ }^{3}$ Toyota Technological Institute, 2-12-1 Hisakata, Tampaku, Nagoya 468-8511, Japan. ${ }^{4}$ Division of Advanced Nuclear Engineering, Pohang University of Science and Technology, Department of Chemical Engineering, Pohang 790-784, Korea. ${ }^{5}$ School of Nano-Bioscience and Chemical Engineering, Ulsan National Institute of Science and Technology, Ulsan 689-798, Korea. Correspondence and requests for materials should be addressed to K.S.K. (email: kim@postech.ac.kr).
} 
$\mathrm{T}$ he oxygen reduction reaction (ORR) is attracting a great deal of attention in electrochemistry due to its technological importance in electrochemical energy conversion and storage devices, such as fuel cells ${ }^{1,2}$ and secondary metal-air batteries $^{3}$. Additionally, the ORR is important in water electrolysis, corrosion, diverse industrial processes and so on ${ }^{4-6}$. Conventionally, platinum $(\mathrm{Pt})$ has been used as an active electrocatalyst for the ORR. However, the use of $\mathrm{Pt}$ in commercial applications as an electrocatalyst is limited due to scarce resources and high price ${ }^{7}$. Traditionally, electrochemical energy conversion and storage devices have suffered from poor ORR activity and stability. These factors make it necessary to develop a low-cost, highly active and durable electrocatalyst to improve the ORR performance. In this regard, the development of nanosize $\mathrm{Pt}$ clusters $\left(\mathrm{Pt}_{\mathrm{n}}\right)$ as an electrocatalyst is highly demanded ${ }^{8,9}$. Synthesis and size control of nanosize $\mathrm{Pt}_{\mathrm{n}}$ is a great challenge, as such new methods for economically feasible largescale production are still required ${ }^{8,9}$. As the activity of Pt catalysts in ORRs is influenced by the supporting material, an ideal supporting material should exhibit the following properties: high electrical conductivity; enhanced reactant gas contact with the electrocatalyst; adequate water handling capability at the cathode; good corrosion resistance; and high specific surface area.

Graphene has attracted much interest in both fundamental and applied science since its 2004 discovery $^{10}$ and large-scale synthesis ${ }^{11-13}$. Owing to the $\mathrm{sp}^{2}$ conjugation in the carbon lattice, electrons move ballistically in graphene even at ambient temperatures, showing excellent performance as electronic devices ${ }^{14,15}$. Graphene displays a high specific surface area (theoretical value, $\left.2,620 \mathrm{~m}^{2} \mathrm{~g}^{-1}\right)^{9}$, good corrosion resistance and excellent conductivity ${ }^{16}$. The unique graphitic basal plane structure should guarantee its durability, as carbon materials with a large graphitic component are more durable ${ }^{17,18}$. Hence, graphene as a catalyst support would lead to an enhanced ORR catalytic activity and durability ${ }^{19}$.

Keeping these important issues in mind, we have designed and synthesized a new highly durable $\mathrm{Pt}_{\mathrm{n}} /$ genomic double-stranded DNA-graphene oxide $\left(\mathrm{Pt}_{\mathrm{n}} / \mathrm{gDNA}-\mathrm{GO}\right)$-based ORR electrocatalyst. We find that the $\mathrm{Pt}_{\mathrm{n}} / \mathrm{gDNA}-\mathrm{GO}$ composite maintains a high ORR onset potential, ORR half-wave potential, mass activity and specific activity, compared with that of Pt nanoparticles/GO and commercial state-of-the-art $20 \mathrm{wt} \% \mathrm{Pt} / \mathrm{C}$ (hereafter abbreviated as $\mathrm{Pt} / \mathrm{C}$; E-TEK, Somerset, NJ) catalysts. The $\mathrm{Pt}_{\mathrm{n}} / \mathrm{gDNA}-\mathrm{GO}$ composite exhibits excellent electrochemical stability compared with the $\mathrm{Pt} / \mathrm{C}$ catalysts in acid medium. Additionally, the $\mathrm{Pt}_{\mathrm{n}} / \mathrm{gDNA}-\mathrm{GO}$ composite exhibits environmental stability and durability over a wide $\mathrm{pH}$ range.

\section{Results}

Synthesis. The $\mathrm{Pt}_{\mathrm{n}} / \mathrm{gDNA}-\mathrm{GO}$ composites were prepared via a three-step synthesis as illustrated in Fig. 1 (see Methods for details). First, the gDNA-GO composites were prepared by mixing an aqueous dispersion of GO (Supplementary Fig. S1a) with a solution of gDNA (Supplementary Fig. S1b), followed by heating. During the heating process, the double-stranded DNA unwinds to form single-stranded DNA, which bridges adjacent GO nanosheets via strong noncovalent interactions. The gDNA-GO composite forms on cooling when the bases of the separate singlestranded DNA chains pair up with each other to reform the gDNA double-helix structure ${ }^{20}$. Second, $\mathrm{Pt}$ (terpy) $\mathrm{Cl}_{2}$ [dichloro $\left(2,2^{\prime}: 6^{\prime}, 2^{\prime \prime}\right.$ terpyridine)platinum(II)] was added to the gDNA$\mathrm{GO}$ suspension and incubated at $27^{\circ} \mathrm{C}$ for 2 days. Studies have shown that the $\mathrm{Pt}(\mathrm{II})$ complexes can bind to the purine, guanine and adenine bases ${ }^{21,22}$. The two $\mathrm{Cl}^{-}$ions coordinated to the $\mathrm{Pt}^{2+}$ ion are labile, therefore they are subsequently removed and the

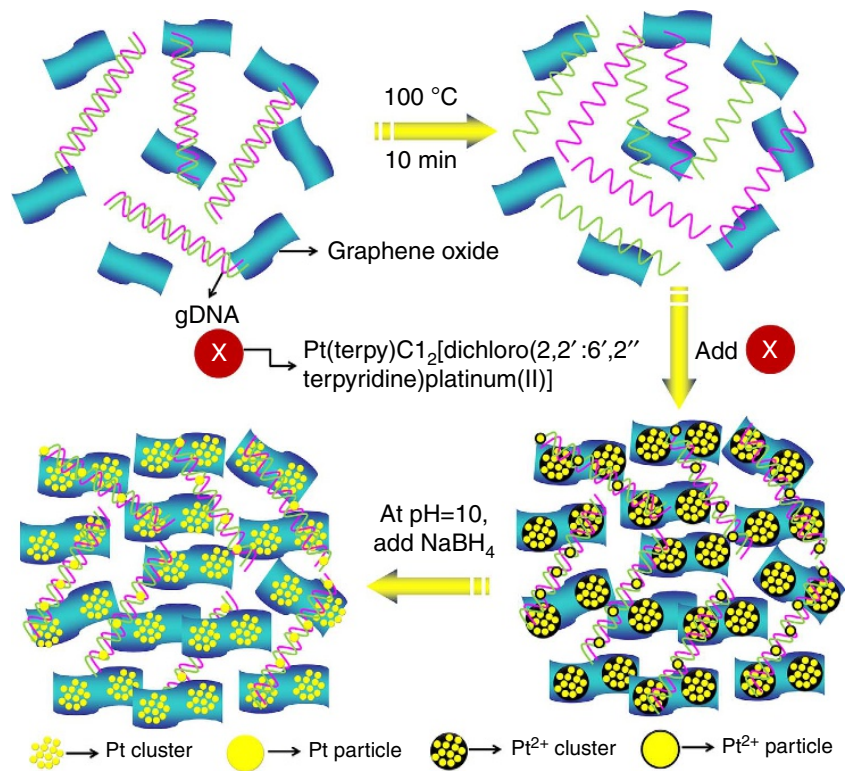

Figure 1 | Synthetic strategy. Schematic for preparing $\mathrm{Pt}_{\mathrm{n}} / \mathrm{gDNA}-\mathrm{GO}$ composites.

free coordination site available to the $\mathrm{Pt}^{2+}$ ion coordinates with the purine bases and forms $\mathrm{Pt}^{2+}-\mathrm{gDNA}$ adducts. This coordination is well known to be due to the strong cation- $\pi$ interaction between $\mathrm{Pt}^{2+}$ and the purine ring ${ }^{23}$. Finally, the composite was reduced using $\mathrm{NaBH}_{4}$ at $27^{\circ} \mathrm{C}$ for 2 days, followed by dialysis. Reduction of $\mathrm{Pt}^{2+}$ to $\mathrm{Pt}^{0}$ led to the deposition of $\mathrm{Pt}_{n}$ on GO as well as Pt nanoparticles in the gDNA, similar to metal reduction in electrochemically active calix nanotubes ${ }^{24,25}$. As a result, a very stable $\mathrm{Pt}_{\mathrm{n}} / \mathrm{gDNA}-\mathrm{GO}$ composite was formed via electrostatic interactions and deposition.

Electrocatalyst characterization. The synthesized products GO, gDNA-GO, Pt nanoparticles/GO and $\mathrm{Pt}_{\mathrm{n}} / \mathrm{gDNA}-\mathrm{GO}$ samples were characterized using Fourier transform infrared spectroscopy, $\mathrm{X}$-ray photoelectron spectroscopy and energy dispersive X-ray (Supplementary Methods). The binding behaviour between gDNA and GO was analysed using Raman spectroscopy (Supplementary Fig. S3). The peak positions at 1,350 and $1,600 \mathrm{~cm}^{-1}$ are ascribed to the D and G Raman bands of graphene, respectively (Supplementary Fig. S3) ${ }^{26}$. In the case of gDNA-GO, the G Raman bands were observed at about $1,595 \mathrm{~cm}^{-1}$. Owing to a small charge transfer from the nucleic acid bases of gDNA chains to GO, a red shift $\left(\sim 5 \mathrm{~cm}^{-1}\right)$ is observed as compared with that of GO, this is similar to the case of wrapping carbon nanotubes with $\mathrm{DNA}^{27}$. The above result suggests that the gDNA is well-bound to the GO sheet. This correlates with the observed ultraviolet-visible results (Supplementary Fig. S4). A red shift $\left(\sim 9 \mathrm{~cm}^{-1}\right)$ is observed in the Pt nanoparticles/GO compared with that of gDNA-GO. This may be attributed to more significant charge transfer. Owing to a change in particle size, a blue shift $\left(\sim 6 \mathrm{~cm}^{-1}\right)$ of the $\mathrm{G}$ band is observed for the $\mathrm{Pt}_{\mathrm{n}} / \mathrm{gDNA}-\mathrm{GO}$ composite as compared with that of Pt nanoparticles/GO $/ \mathrm{GO}^{28}$. This observed blue shift indicates that the $\mathrm{Pt}_{\mathrm{n}}$ firmly attaches to the surface of the gDNA-GO composite ${ }^{29}$. The attachment of the Pt particles and $\mathrm{Pt}_{\mathrm{n}}$ to the gDNA in the $\mathrm{Pt}_{\mathrm{n}} / \mathrm{gDNA}-\mathrm{GO}$ and $\mathrm{Pt} / \mathrm{gDNA}$ catalysts is further confirmed by electrophoresis and energy-dispersive X-ray (EDX) analysis (Supplementary Fig. S5a,b).

The structures of the GO, gDNA-GO, Pt nanoparticles/GO and $\mathrm{Pt}_{\mathrm{n}} / \mathrm{gDNA}-\mathrm{GO}$ samples were characterized using highresolution scanning electron microscopy. In all of the samples, the 
continuous silk wave morphology associated with GO is observed due to strong interactions between the GO layers after evaporation of the solvent (Supplementary Fig. S6) ${ }^{30,31}$. Owing to the small size of the $\mathrm{Pt}_{\mathrm{n}}$ and $\mathrm{Pt}$ nanoparticles, the $\mathrm{Pt}$ nanoparticles/GO and $\mathrm{Pt}_{\mathrm{n}} / \mathrm{gDNA}-\mathrm{GO}$ samples were analysed using low-resolution transmission electron microscopy (LRTEM) and high-resolution transmission electron microscopy (HRTEM). The LRTEM image of the surface of the $\mathrm{Pt}_{n} / \mathrm{gDNA}-\mathrm{GO}$ composite shows $\mathrm{Pt}_{n}$ evenly dispersed on the GO surface (Supplementary Fig. S7a). The HRTEM image of $\mathrm{Pt}_{\mathrm{n}} / \mathrm{gDNA}-$ GO clearly shows well-defined single $\mathrm{Pt}_{\mathrm{n}}$, as displayed in Fig. 2a. The sizes of indivisible $\mathrm{Pt}_{\mathrm{n}}$ are $\sim 1 \mathrm{~nm}$. Representative LRTEM and HRTEM images of the surface of the Pt nanoparticles/GO are shown in Fig. 2b and Supplementary Fig. S7b. The Pt nanoparticles are well dispersed with some agglomeration on the surface of GO. From HRTEM analysis, the size of individual nanoparticles are $\sim 2-3 \mathrm{~nm}$. In the case of $\mathrm{Pt} / \mathrm{C}$, the LRTEM image clearly shows an even dispersion of Pt nanoparticles on the surface of spherical carbon (Supplementary Fig. S7c). The HRTEM image (Fig. 2c) shows that the size of single nanoparticles are $\sim 2-3 \mathrm{~nm}$, similar to the $\mathrm{Pt}$ nanoparticles/GO sample. We further analysed nanocluster and nanoparticle size distributions from the HRTEM images of the $\mathrm{Pt}_{\mathrm{n}} / \mathrm{gDNA}-\mathrm{GO}$ composite, $\mathrm{Pt}$ nanoparticles/GO and $\mathrm{Pt} / \mathrm{C}$ catalysts. A size distribution analysis of the $\mathrm{Pt}_{\mathrm{n}}$ reveals an average size of $1 \mathrm{~nm}$,
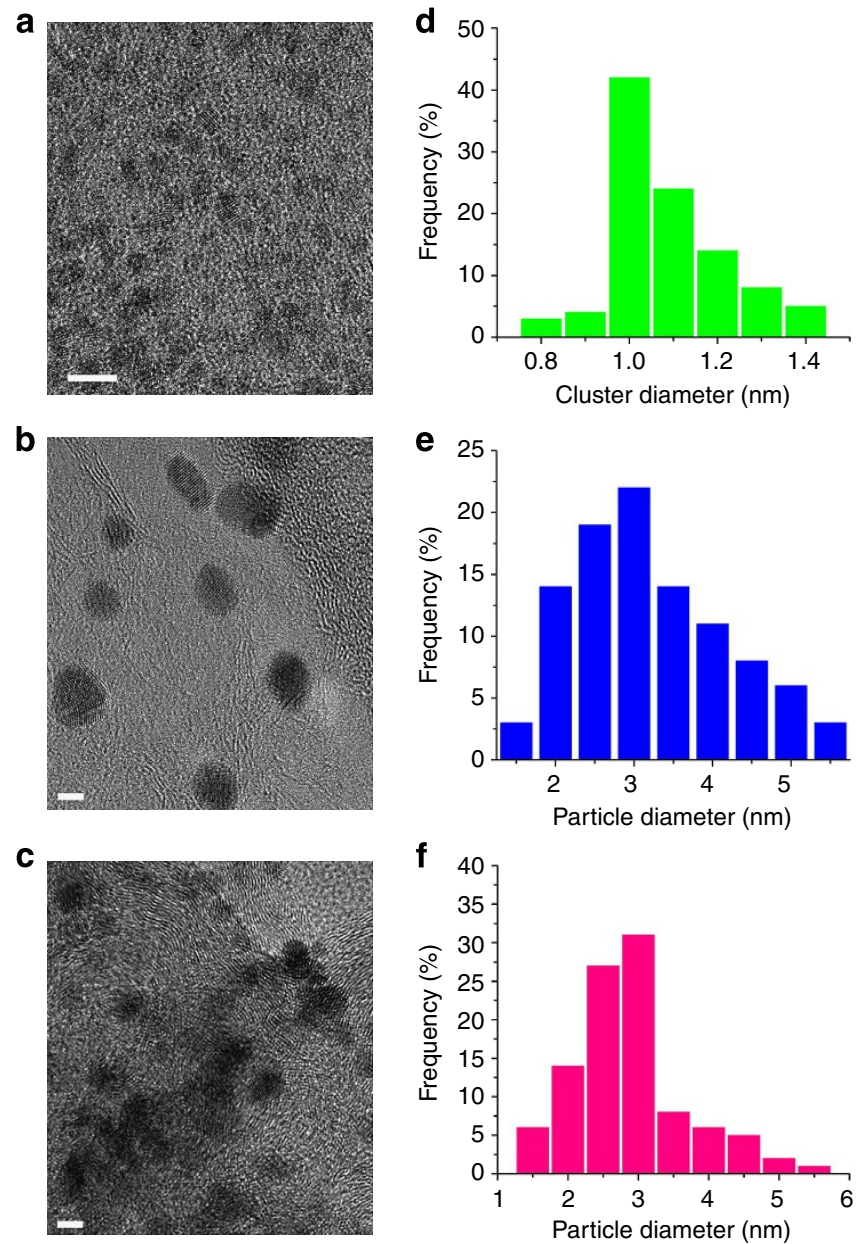

Figure 2 | TEM images and size histograms. (a-c) HRTEM images of the $\mathrm{Pt}_{\mathrm{n}} \mathrm{gDNA}-\mathrm{GO}$ composite, $\mathrm{Pt}$ nanoparticles/GO and Pt/C catalyst. Scale bars, $2 \mathrm{~nm}$. (d) Histograms of Pt cluster sizes in the $\mathrm{Pt}_{\mathrm{n}} / \mathrm{gDNA}-\mathrm{GO}$ composite, (e) Pt particle sizes in the Pt nanoparticles/GO catalyst and (f) $\mathrm{Pt}$ particle sizes in the $\mathrm{Pt} / \mathrm{C}$ catalyst. ranging from 0.8 to $1.4 \mathrm{~nm}$ (Fig. 2d). However, in the case of Pt nanoparticles/GO and $\mathrm{Pt} / \mathrm{C}$, the average size of the $\mathrm{Pt}$ nanoparticles is $\sim 3 \mathrm{~nm}$, ranging from 1 to $4-5 \mathrm{~nm}$ (Fig. 2e,f).

Electrocatalytic performance. The catalytic activity of the $\mathrm{Pt}_{\mathrm{n}} / \mathrm{gDNA}-\mathrm{GO}$ composite was compared with the Pt nanoparticles/GO and Pt/C catalysts. Cyclic voltammetry (CV) curves for the catalysts at room temperature in $\mathrm{N}_{2}$-saturated $0.1 \mathrm{M}$ $\mathrm{HClO}_{4}$ are shown in Supplementary Fig. S14. The CV curves exhibit two distinctive potential regions associated with the under-potentially deposited hydrogen $\left(\mathrm{H}_{\text {upd }}\right)$ adsorption/desorption processes $\left(\mathrm{H}^{+}+\mathrm{e}^{-}=\mathrm{H}_{\text {upd }}\right)$ between $0<E<0.37 \mathrm{~V}$ and the formation of an $\mathrm{OH}_{\mathrm{ad}}$ layer $\left(2 \mathrm{H}_{2} \mathrm{O}=\mathrm{OH}_{\mathrm{ad}}+\mathrm{H}_{3} \mathrm{O}^{+}+\mathrm{e}^{-}\right)$ beyond $\sim 0.6 \mathrm{~V}$ (ref. 32). The specific electrochemically active surface area (EASA) was calculated by measuring the charge collected in the $\mathrm{H}_{\text {upd }}$ adsorption/desorption region after doublelayer correction, and assuming that a constant $0.21 \mathrm{mC} \mathrm{cm}^{-2}$ charge is required to oxidize a monolayer of $\mathrm{H}_{2}$ on a polycrystalline Pt electrode (see Supplementary Methods). The specific EASA of theses catalysts were measured to be 66.6, 57.3 and $74.1 \mathrm{~m}^{2} \mathrm{~g}^{-1}$ for the $\mathrm{Pt}_{\mathrm{n}} / \mathrm{gDNA}-\mathrm{GO}$ composite, Pt nanoparticles/GO and $\mathrm{Pt} / \mathrm{C}$ catalyst, respectively. We further performed CO-stripping CV (Supplementary Methods) to obtain the accurate catalytic activity. Representative CO-stripping CV curves for the $\mathrm{Pt}_{\mathrm{n}} / \mathrm{gDNA}-\mathrm{GO}$, Pt nanoparticles/GO and $\mathrm{Pt} / \mathrm{C}$ catalysts are shown in Supplementary Fig. S15. The calculated EASA area of Pt nanoparticles/GO and $\mathrm{Pt} / \mathrm{C}$ are $\sim 59.1$ and $\sim 73.4 \mathrm{~m}^{2} \mathrm{~g}^{-1}$, respectively. This value is calculated by integrating the $\mathrm{CO}$ oxidation peak of the first $\mathrm{CO}$-stripping cycle, assuming an oxidation charge value of $420 \mu \mathrm{C} \mathrm{cm}^{-2}$ for a monolayer of CO adsorbed on a smooth $\mathrm{Pt}$ surface ${ }^{33-38}$. However, the EASA area of $\mathrm{Pt}_{\mathrm{n}} / \mathrm{g}$ DNA-GO is $\sim 149.8 \mathrm{~m}^{2} \mathrm{~g}^{-1}$, which is more than double that estimated from the $\mathrm{H}_{\text {upd }}$ adsorption/desorption experiments. This discrepancy in the EASA values determined from $\mathrm{H}_{\text {upd }}$ adsorption/desorption and from CO-stripping experiments could be due to the presence of a large double-layer charge in GO. This increased ESA of the $\mathrm{Pt}_{\mathrm{n}} / \mathrm{gDNA}-\mathrm{GO}$ can significantly improve catalytic activity towards the ORR compared with the other two catalysts.

The ORR catalytic activity and kinetics in an $\mathrm{O}_{2}$-saturated $0.1 \mathrm{M} \mathrm{HClO}_{4}$ solution were studied by using a glassy carbon rotating-disk electrode at room temperature. Polarization curves for the ORR on these three catalysts are displayed in Fig. 3a-d and Supplementary Fig. S16a-d. The onset potentials for the ORR are $\sim 1.01, \sim 0.99$ and $\sim 0.95 \mathrm{~V}$ for the $\mathrm{Pt}_{\mathrm{n}} / \mathrm{gDNA}-\mathrm{GO}$ composite, $\mathrm{Pt}$ nanoparticles/GO and $\mathrm{Pt} / \mathrm{C}$, respectively. A higher ORR half-wave potential was observed for the $\mathrm{Pt}_{\mathrm{n}} / \mathrm{gDNA}-\mathrm{GO}$ composite $(\sim 0.90 \mathrm{~V})$ compared with the $\mathrm{Pt}$ nanoparticles/GO $(\sim 0.83 \mathrm{~V})$ and $\mathrm{Pt} / \mathrm{C}(\sim 0.85 \mathrm{~V})$ catalysts. The increased onset and half-wave potential observed in the $\mathrm{Pt}_{\mathrm{n}} / \mathrm{gDNA}-\mathrm{GO}$ composites are due to the reduction of $\mathrm{O}_{2}$ molecules via $\mathrm{Pt}_{\mathrm{n}}$ as well as the $\mathrm{Pt}$ nanoparticles fixed in the purine bases (Supplementary Fig. S17). Pt nanoparticles/GO shows a lower current density of $0.9 \mathrm{~V}$ (Supplementary Fig. S16a) than the $\mathrm{Pt}_{\mathrm{n}} / \mathrm{gDNA}-\mathrm{GO}$ composite. This indicates that the kinetic current is lower when $\mathrm{Pt}$ nanoparticles are loaded on GO. Additionally, the diffusionlimiting potential region is short for the Pt nanoparticles/ $\mathrm{GO}$, resulting in a faster kinetic current drop with increasing potential. For the $\mathrm{Pt}_{\mathrm{n}} / \mathrm{gDNA}-\mathrm{GO}$ composite (Fig. 3a), the mixed kinetic-diffusion control region occurs between 0.75 and $1.01 \mathrm{~V}$, which is higher than that of the $\mathrm{Pt} / \mathrm{C}$ catalyst (between 0.7 and $0.9 \mathrm{~V}$, Supplementary Fig. S16b). As represented in Fig. $3 c$, the $\mathrm{Pt}_{\mathrm{n}} / \mathrm{gDNA}-\mathrm{GO}$ composite showed a mass activity of $0.317 \mathrm{mA \mu g}$ metal at $0.9 \mathrm{~V}$ versus a reversible hydrogen electrode. This value is 3.3 and 2.6 times higher than that of 

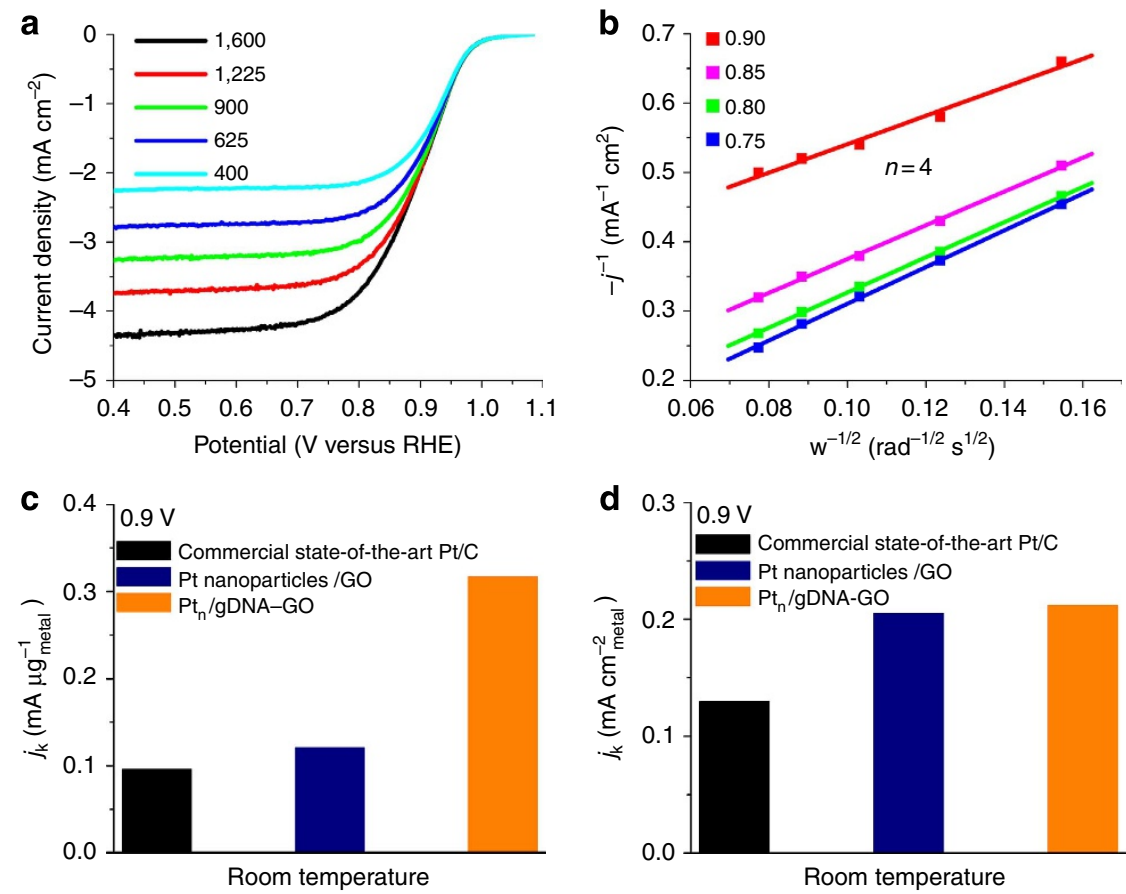

Figure 3 | ORR catalytic properties. (a) ORR polarization curves of the $\mathrm{Pt}_{n} / g D N A-G O$ composite in an $\mathrm{O}_{2}$-saturated $0.1 \mathrm{M} \mathrm{HClO}_{4}$ solution with a sweep rate of $10 \mathrm{mVs}^{-1}$ at different rotation speeds. (b) Corresponding K-L plots at different potentials. (c) Mass activity and (d) specific activity at $0.9 \mathrm{~V}$ versus reversible hydrogen electrode (RHE) for different catalysts. Mass and specific activities are given as kinetic current densities $\left(j_{k}\right)$ normalized in reference to the loading amount of metal and EASA (EASA from CO stripping), respectively. The metal loading on the rotating-disk electrode was $\sim 11.3 \mu \mathrm{g} \mathrm{cm}^{-2}$ for $\mathrm{Pt}_{\mathrm{n}} / \mathrm{gDNA}-\mathrm{GO}$, Pt nanoparticles/GO and Pt/C. In a the current density was normalized in reference to the geometric area of a rotatingdisk electrode $\left(0.0707 \mathrm{~cm}^{2}\right)$.

the Pt/C (0.096 mA $\mu g_{\text {metal }}^{-1}$, Fig. 3c) and the Pt nanoparticles/GO $\left(0.121 \mathrm{~mA} \mu \mathrm{g}_{\text {metal }}^{-1}\right.$, Fig. $\left.3 \mathrm{c}\right)$ catalyst, respectively. Our $\mathrm{Pt}_{\mathrm{n}} / \mathrm{gDNA}-$ GO composite displays one of the highest mass activities for the ORR (Supplementary Table S3).

The $\mathrm{Pt}_{\mathrm{n}} / \mathrm{gDNA}-\mathrm{GO}$ composite had a specific activity (that is, kinetic current per unit surface area of catalyst) of 1.63 times that of the $\mathrm{Pt} / \mathrm{C}$ catalysts and 1.03 times that of the Pt nanoparticles/ GO (Fig. 3d). Linearity in Koutecky-Levich (K-L) plots, as well as parallelism of the fitting lines is known to correspond to firstorder reaction kinetics with respect to concentration of dissolved $\mathrm{O}_{2}$ molecules $^{39}$. From the slopes of the K-L plots (Fig. 3b), the number of electrons transferred $(n)$ during the ORR was calculated to be $\sim 4.0$ at $0.75-0.9 \mathrm{~V}$ for the $\mathrm{Pt}_{\mathrm{n}} / \mathrm{gDNA}-\mathrm{GO}$ composite, which is similar to the number of electrons transferred using the Pt/C catalyst ( $n \sim 3.7$, Supplementary Fig. S16d). The increased ORR onset potential, half-wave potential, mass activity and specific activity exhibited by the $\mathrm{Pt}_{\mathrm{n}} / \mathrm{gDNA}-\mathrm{GO}$ composite could be due to significant changes in the active surface area of $\mathrm{Pt}_{\mathrm{n}}$ and chemical interactions between $\mathrm{Pt}$ and GO, which can alter the electron density in the $d$-orbitals of $\mathrm{Pt}$, thereby enhancing the ORR catalytic activity. Additionally, a more facile transport of the reduced species occurs in the gDNA-GO composites, due to strong binding between gDNA and GO, which creates an increased electronic conductivity and corrosion resistance.

Accelerated degradation tests (ADTs) were conducted by cycling the catalysts in an $\mathrm{O}_{2}$-saturated $\mathrm{HClO}_{4}$ solution at 0.6 and $1.2 \mathrm{~V}$ at a sweep rate of $50 \mathrm{mV} \mathrm{s}^{-1}$, while $\mathrm{CV}$ curves between 0 and $1.4 \mathrm{~V}$ were recorded to compare the EASA during potential cycling. Figure $4 \mathrm{a}-\mathrm{c}$ show the 10th and 10,000 CV curves for the $\mathrm{Pt}_{\mathrm{n}} / \mathrm{gDNA}-\mathrm{GO}$ composite, $\mathrm{Pt}$ nanoparticles/GO and $\mathrm{Pt} / \mathrm{C}$ catalysts. After cycling, the CV measurements showed a loss of $\sim 5.8 \%$ in EASA for the $\mathrm{Pt}_{\mathrm{n}} / \mathrm{gDNA}-\mathrm{GO}$ composite, $\sim 39 \%$ for the $\mathrm{Pt} / \mathrm{C}$ and $\sim 33 \%$ for the $\mathrm{Pt}$ nanoparticles/GO catalyst (Fig. 4d). ORR activities after the ADT were measured for all samples in $\mathrm{O}_{2}$-saturated $\mathrm{HClO}_{4}$ solution. Supplementary Fig. S18a-c show the polarization curves for the $\mathrm{Pt}_{\mathrm{n}} / \mathrm{gDNA}-\mathrm{GO}$ composite, $\mathrm{Pt}$ nanoparticles/GO and $\mathrm{Pt} / \mathrm{C}$ catalyst before and after the ADT. In the mixed kinetic-diffusion control region, the $\mathrm{Pt}$ nanoparticles/GO and $\mathrm{Pt} / \mathrm{C}$ catalyst show a large current drop after the ADT, while there is almost no change for the $\mathrm{Pt}_{\mathrm{n}}$ / gDNA-GO composite (Supplementary Fig. S18a-c). To reveal the mechanism of the durability enhancement, the catalysts were collected by sonicating the glassy carbon disk electrode in ethanol after the ADT, and their structures were observed by transmission electron microscopy (TEM; Fig. 4e-g). The Pt nanoparticles/GO catalyst shows an increase in nanoparticle size from $\sim 3$ to $\sim 20 \mathrm{~nm}$ after the ADT (Fig. 4f), while the Pt/C catalyst shows an increase in size from $\sim 3$ to $\sim 10 \mathrm{~nm}$ after the ADT (Fig. $4 \mathrm{~g}$ ). The increase in Pt nanoparticle size is due to Ostwald ripening, which is consistent with the observed decrease in EASA for these catalysts. Additionally, fewer nanoparticles are observed in the $\mathrm{Pt}$ nanoparticles/GO and $\mathrm{Pt} / \mathrm{C}$ samples after the ADT test. This is due to corrosion of $\mathrm{GO}$ and carbon, which leads to the detachment of Pt nanoparticles from the support material. In contrast, the $\mathrm{Pt}_{\mathrm{n}} / \mathrm{gDNA}-\mathrm{GO}$ composite displayed the same features before and after the ADT (Supplementary Fig. S18a) with $\mathrm{Pt}_{\mathrm{n}}$ sizes between 1.0 and $1.5 \mathrm{~nm}$ and uniform nanoparticle distribution (Fig. 4e).

The long-term stabilities of the catalysts were determined by $\mathrm{CV}$ cycling in a $\mathrm{N}_{2}$-saturated $0.1 \mathrm{M} \mathrm{HClO}_{4}$ solution between 0 and 1.4 V. Supplementary Fig. S19a-c shows the 20th and 10,000 $\mathrm{CV}$ curves for the catalysts, and a clear decrease in activity is observed for the $\mathrm{Pt}$ nanoparticles/GO and $\mathrm{Pt} / \mathrm{C}$ catalysts. For a clear observation of CV stability, the normalized EASA for the catalysts was plotted (versus 20 cycles) as a function of the 
a

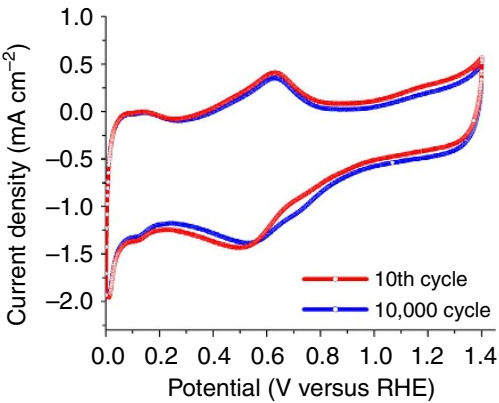

C

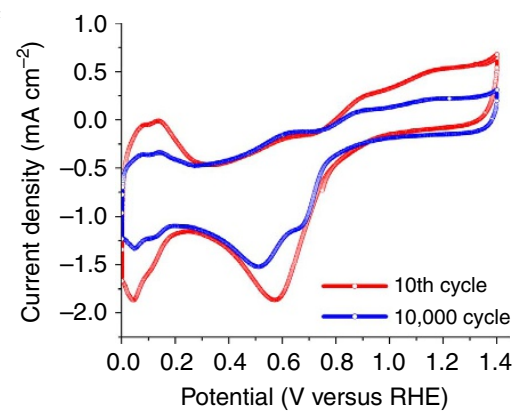

b

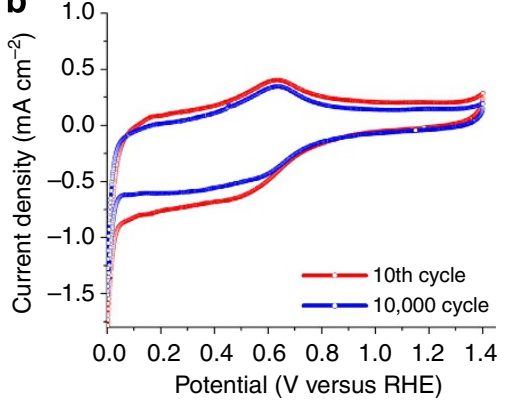

d

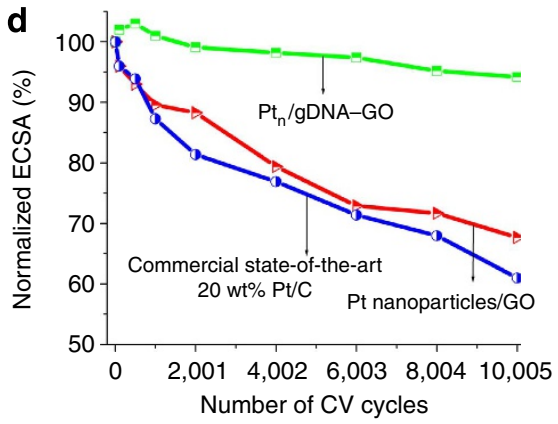

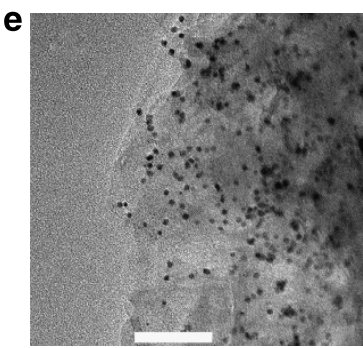
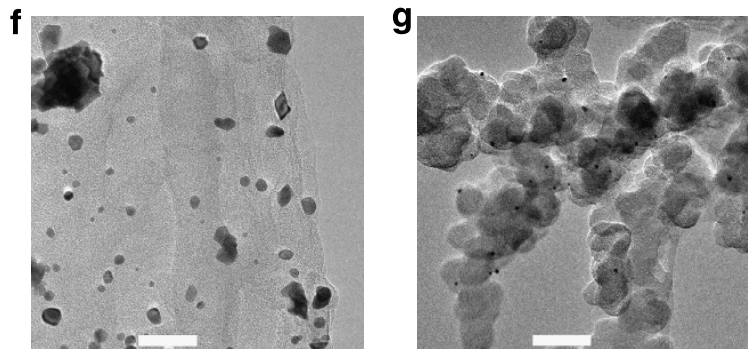

Figure 4 | ADT and TEM microstructure of the catalysts after ADT. CV curves of 10th and 10,000 cycle for the (a) Pt $/ t_{n} / g D A-G O$ composite,

(b) Pt nanoparticles/GO and (c) Pt/C catalyst. (d) Comparison of decrease in EASA for the catalysts. The durability test was carried out for the three samples in an $\mathrm{O}_{2}$-saturated $0.1 \mathrm{M} \mathrm{HClO}_{4}$ solution with the cyclic potential sweeping between 0.6 and $1.2 \mathrm{~V}$ versus reversible hydrogen electrode (RHE) at a scan rate of $50 \mathrm{mVs}^{-1}$. The metal loading on the rotating-disk electrode was $11.3 \mu \mathrm{g} \mathrm{cm}^{-2}$ and current densities were normalized in reference to the geometric surface area of a rotating-disk electrode $\left(0.0707 \mathrm{~cm}^{2}\right)$. $(\mathbf{e}-\mathbf{g})$ TEM images of the $\mathrm{Pt} n \mathrm{gDNA}-\mathrm{GO}, \mathrm{Pt}$ nanoparticles/GO and Pt/C catalyst after the ADT. Scale bars, $20 \mathrm{~nm}$.

number of CV cycles (Supplementary Fig. S19d). A decrease in EASA of $\sim 6 \%$, compared with the initial EASA, is observed for $\mathrm{Pt}_{\mathrm{n}} / \mathrm{gDNA}-\mathrm{GO}$ composite after 10,000 cycles, while a decrease in EASA of $\sim 48 \%$ and $\sim 60 \%$ is observed for the Pt nanoparticles/ $\mathrm{GO}$ and $\mathrm{Pt} / \mathrm{C}$ catalysts, respectively. The results of the long-term stability test are consistent with the findings of the ADT test. The observed enhanced stability can be due to the strong interaction between $\mathrm{Pt}_{\mathrm{n}}, \mathrm{gDNA}$ and $\mathrm{GO}$. The $\mathrm{Pt}_{\mathrm{n}}$ are stabilized by coordination with the purine moieties in the gDNA as well as graphene ${ }^{40,41}$.

Environmental and pH stability. The long-time environmental stability of the $\mathrm{Pt}_{\mathrm{n}} / \mathrm{gDNA}-\mathrm{GO}$ composite at various $\mathrm{pH}$ conditions ( $\mathrm{pH}=1-13)$ was conducted (Fig. 5a). It can be seen that the $\mathrm{Pt}_{\mathrm{n}} / \mathrm{gDNA}-\mathrm{GO}$ composite is stable under these harsh environmental conditions at room temperature for 2 months. Besides the visually observed environmental stability, we also performed ORR activity experiments over a wide range of $\mathrm{pH}$ values (Fig. 5b). As can be seen in Fig. $5 b$, the $\mathrm{Pt}_{\mathrm{n}} / \mathrm{gDNA}-\mathrm{GO}$ composite displayed a constant relative mass activity over a wide $\mathrm{pH}$ range $(1-13 \mathrm{pH})$, which means that the composite is extremely stable at various $\mathrm{pH}$ values. On the other hand, the ORR relative mass activities for $\mathrm{Pt}$ nanoparticles/GO and $\mathrm{Pt} / \mathrm{C}$ catalysts (Fig. $5 \mathrm{~b}$ ) vary as the $\mathrm{pH}$ a
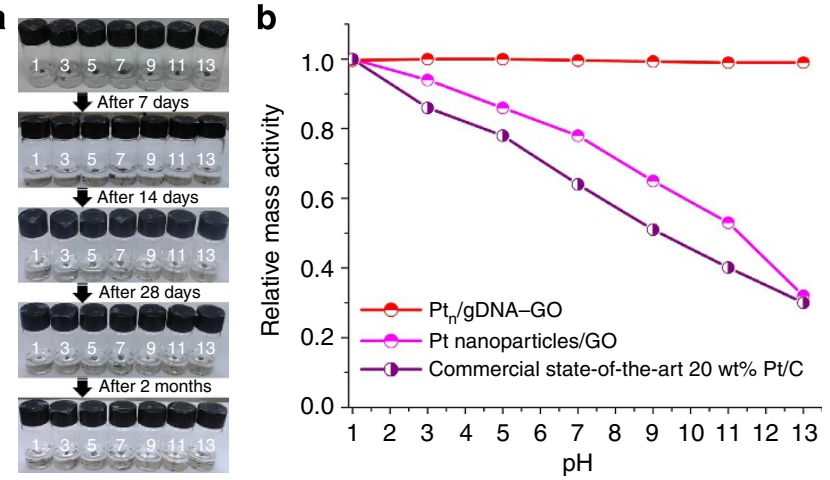

Figure 5 | Solution phase and pH stability. (a) Effects of $\mathrm{pH}$ on the $\mathrm{Pt}_{\mathrm{n}} / \mathrm{gDNA}-\mathrm{GO}$ composite. The $\mathrm{pH}$ value is numbered on each bottle. The $\mathrm{Pt}_{\mathrm{n}} / \mathrm{gDNA}-\mathrm{GO}$ composite was placed into the respective solutions, and allowed to stand at room temperature for 8 weeks. (b) The relative mass activity of the catalysts measured in $\mathrm{O}_{2}$-saturated electrolytes of varying $\mathrm{pH}$ with a scan rate of $10 \mathrm{mVs}^{-1}$ at a rotation speed of 1,600 r.p.m.

changes, which is likely to arise from the instability of the composites at various $\mathrm{pH}$ values. This excellent environmental and $\mathrm{pH}$ stability of the $\mathrm{Pt}_{\mathrm{n}} / \mathrm{gDNA}-\mathrm{GO}$ composite could be attributed 
to the strong binding of the gDNA chains to GO sheets through multiple noncovalent interactions. These noncovalent interactions include $\pi-\pi$ stacking ${ }^{42}$ between the bases of gDNA and graphitic domains of GO sheets, as well as hydrogen bonding between the amines of the gDNA bases and the oxygencontaining functional groups of the GO sheets ${ }^{43}$.

\section{Discussion}

Herein we described the synthetic method to produce a novel $\mathrm{Pt}_{\mathrm{n}} / \mathrm{gDNA}-\mathrm{GO}$ composite. The synthesized composite was characterized by Fourier transform infrared (FTIR), Raman, ultraviolet-visible, scanning electron microscopy, TEM, HRTEM, EDX and X-ray photoemission spectroscopy (XPS), which clearly demonstrate that the $\mathrm{Pt}_{\mathrm{n}} / \mathrm{gDNA}-\mathrm{GO}$ composite is successfully synthesized. The interactions between gDNA and GO may provide an efficient approach for positioning Pt ions to form the Pt nanoclusters on the surface of GO. Thus, gDNA holds great promise as a cost-effective and environmentally friendly template for large-scale production of $\mathrm{Pt}_{\mathrm{n}} / \mathrm{GO}$. This newly developed method suggests a technique to synthesize other types of GOsupported nanoclusters, such as $\mathrm{Ag}, \mathrm{Pd}, \mathrm{Au}$ and so on. The electrochemical data show that the as-synthesized $\mathrm{Pt}_{\mathrm{n}} / \mathrm{gDNA}-\mathrm{GO}$ composite exhibits a greater ORR onset potential, ORR half-wave potential, specific activity and mass activity for the ORR compared with $\mathrm{Pt}$ nanoparticles/GO and $\mathrm{Pt} / \mathrm{C}$ catalysts. The $\mathrm{Pt}_{\mathrm{n}} / \mathrm{gDNA}-\mathrm{GO}$ composite displays an excellent accelerated durability test $(10,000$ cycles) and a long-term CV stability (10,000 cycles) as compared with Pt nanoparticles/GO and Pt/C catalysts in acidic media. Furthermore, good corrosion resistance and high conductivity of $\mathrm{Pt}_{\mathrm{n}} / \mathrm{gDNA}-\mathrm{GO}$ composites may account for the observed enhanced performance. These properties make us believe that the $\mathrm{Pt}_{\mathrm{n}} / \mathrm{gDNA}-\mathrm{GO}$ composites might have a promising future in applications such as fuel cells, supercapacitors, biosensors, nanoscale electronics, drug delivery and imaging of cancer cells ${ }^{44-47}$. This is due to their ability to promote faster oxygen reduction kinetics, their robustness against environmental degradation and electrochemical stability.

\section{Methods}

Genomic double-stranded deoxyribonucleic acid. Application of pure gDNA in material sciences has added a new horizon to the conventional materials science landscape. To obtain pure gDNA from plant leaves at a large scale is likely to be a difficult task due to accumulation of polysaccharide and phenolic compounds. In this regard, we took advantage of the model plant Arabidopsis thaliana, which contains a smaller amount of polysaccharide and phenolic compounds, to isolate gDNA on a large scale. The $\mathrm{A}_{260} / \mathrm{A}_{280}$ ratio of gDNA was 1.83 , which shows that the large-scale isolated gDNA $\left(6 \mathrm{mg} \mathrm{ml}^{-1}\right)$ was pure enough to use in the present study. Isolated gDNA was subjected to hydrodynamic shearing by exposure to brief periods of sonication to generate gDNA fragments of size 300-700 base pairs (bp; Supplementary Fig. S1d). Utilizing a specific sonication cycle we successfully sheared more than $95 \%$ of the total gDNA to the expected size (Supplementary Fig. S1d: lanes 1 and 2, and lane 3 lower bands) compared with unsonicated gDNA (Supplementary Fig. S1d: lane 3 upper band). The detailed procedures for isolation of gDNA and synthesis of GO are given in Supplementary information.

Synthesis of gDNA-GO composites. To an aqueous GO $(200 \mathrm{mg} / 50 \mathrm{ml})$ dispersion, $4 \mathrm{ml}$ of an aqueous gDNA solution $\left(6 \mathrm{mg} \mathrm{ml}^{-1}\right)$ was added and the mixture was sonicated for $4 \mathrm{~h}$. Finally, the mixture was heated at $100{ }^{\circ} \mathrm{C}$ for $10 \mathrm{~min}$. After cooling to room temperature, the gDNA-GO composite solution was kept for further reactions.

Synthesis of $\mathbf{P t}_{\mathbf{n}} / \mathbf{g D N A}-\mathbf{G O}$ composites and $\mathbf{P t}$ nanoparticles/GO. The synthesis of $20 \mathrm{wt} \% \mathrm{Pt}_{\mathrm{n}} / \mathrm{gDNA}-\mathrm{GO}$ composites involved mixing $110 \mathrm{mg}$ of $\mathrm{Pt}$ (terpy) $\mathrm{Cl}_{2}$ [dichloro $\left(2,2^{\prime}: 6^{\prime}, 2^{\prime \prime}\right.$ terpyridine)platinum(II)] with $54 \mathrm{ml}$ of a gDNA$\mathrm{GO}$ suspension followed by incubation at $27^{\circ} \mathrm{C}$ for 2 days with vigorous stirring. Finally, $50 \mathrm{ml} \mathrm{NaBH}_{4}$ aqueous solution with a concentration of $5 \mathrm{mg} \mathrm{ml}^{-1}$ was added and reduction was allowed to proceed for 2 days at $27^{\circ} \mathrm{C}$. At the end of the experiments, the solution was dialysed through cellulose membranes to remove free $\mathrm{Pt}$ and $\mathrm{NaBH}_{4}$ ions that were not bound to the gDNA-GO composites.
For the synthesis of $20 \mathrm{wt} \% \mathrm{Pt}$ nanoparticles/GO the same procedure was followed, with a gDNA-GO suspension replaced by a GO suspension. The schematic diagram for the synthesis of Pt nanoparticles/GO composites is depicted in Supplementary Fig. S20.

Characterization. Atomic force microscopy (AFM) images were recorded using an AFM, Bruker-N8 NEOS. The sample was prepared by depositing an aqueous GO dispersion onto a clean silicon surface and then drying the sample under vacuum at room temperature. The gDNA AFM sample was prepared by dropping a $1.0 \mathrm{ml}$ of extracted gDNA solution directly onto to a clean silicon surface. FTIR spectra were recorded in $\mathrm{KBr}$ pellets using a Bruker FTIR. Measurements of micro Raman spectra were carried out using a Senterra Raman Scope system with a 532-nm wavelength incident laser light and $20 \mathrm{~mW}$ power. Ultraviolet-visible absorption spectra were recorded with a Shimadzu UV-2401PC spectrophotometer. The samples were dispersed in deionized (DI) water for optical measurements. The morphologies of the resulting products were characterized using a field-emission scanning electron microscope (JEOL, FEG-XL 30S) with an acceleration voltage of 5 KV. LRTEM and HRTEM observations were carried out in a JEM-2200FS (Cs corrected STEM) electron microscope with an accelerating voltage of $200 \mathrm{kV}$. The TEM specimens were prepared by dispersing the platinum clusters/particles on a copper grid. XPS analysis was performed with an ESCALAB-220I-XL (ThermoElectron, VG Company) device. XPS was used to characterize the GO, gDNA-GO, $\mathrm{Pt}$ nanoparticles/GO, $\mathrm{Pt} / \mathrm{C}$ and $\mathrm{Pt}_{\mathrm{n}} / \mathrm{gDNA}-\mathrm{GO}$ catalysts after deposition of the as-synthesized samples onto a silicon wafer.

Electrochemical characterization. CVs were recorded by scanning the electrode potential from 0.0 to $1.4 \mathrm{~V}$ (versus reversible hydrogen electrode) at a scan rate of $50 \mathrm{mV} \mathrm{s}^{-1}$. The VSP-Modular 2 Channels Potentiostat/Galvanostat/EIS (Bio-Logic Science Instruments) was calibrated with respect to an $\mathrm{Ag} / \mathrm{AgCl}$ electrode. $\mathrm{CV}$ measurements were carried out in an $\mathrm{N}_{2}$-saturated $0.1 \mathrm{M} \mathrm{HClO}_{4}$ solution at room temperature. Rotating-disk electrode measurements were carried out in an $\mathrm{O}_{2}$-saturated $0.1 \mathrm{M} \mathrm{HClO}_{4}$ solution at room temperature using a rotating-disk electrode system for ORR calibration. Linear sweep voltammograms were recorded by scanning the disk potential from 1.1 to $0.4 \mathrm{~V}$ (versus reversible hydrogen electrode) at a scan rate of $10 \mathrm{mV} \mathrm{s}^{-1}$. For $\mathrm{CV}$ and rotating-disk electrode experiments, a three-electrode configuration was used, consisting of a modified glassy carbon electrode (geometric area of $0.0707 \mathrm{~cm}^{2}$ ) as the working electrode, $\mathrm{Ag} / \mathrm{AgCl}$ electrode and Pt wire as a counter electrode. See Supplementary Methods for further details.

\section{References}

1. Vayssilov, G. N. et al. Support nanostructure boosts oxygen transfer to catalytically active platinum nanoparticles. Nat. Mater. 10, 310-315 (2011).

2. Wu, G., More, K. L., Johnston, C. M. \& Zelenay, P. High-performance electrocatalysts for oxygen reduction derived from polyaniline, iron, and cobalt. Science 332, 443-447 (2011).

3. Dewi, E. L., Oyaizu, K., Nishide, H. \& Tsuchida, E. Electrocatalysis for dioxygen reduction by a $\mu$-oxo decavanadium complex in alkaline medium and its application to a cathode catalyst in air batteries. J. Power Sources 130, 286-290 (2004).

4. Dau, H. et al. The mechanism of water oxidation: from electrolysis via homogeneous to biological catalysis. Chem. Cat. Chem. 2, 724-761 (2010).

5. Dewi, E. L., Oyaizu, K. \& Tsuchida, E. Four-electron reduction of dioxygen catalyzed by a decavanadium complex. Inorg. Chim. Acta 342, 316-318 (2003)

6. Lai, M. E. \& Bergel, A. Electrochemical reduction of oxygen on glassy carbon: catalysis by catalase. J. Electroanal. Chem. 494, 30-40 (2000).

7. Tiwari, J. N., Tiwari, R. N. \& Kim, K. S. Zero-dimensional, one-dimensional, two-dimensional and three-dimensional nanostructured materials for advanced electrochemical energy devices. Prog. Mater. Sci. 57, 724-803 (2012).

8. Shrestha, S., Liu, Y. \& Mustain, W. E. Electrocatalytic activity and stability of Pt clusters on state-of-the-art supports: a review. Catal. Rev. 53, 256-336 (2011)

9. Yamamoto, K. et al. Size-specific catalytic activity of platinum clusters enhances oxygen reduction reactions. Nat. Chem. 1, 397-402 (2009).

10. Novoselov, K. S. et al. Electric field effect in atomically thin carbon films. Science 306, 666-669 (2004).

11. Kim, K. S. et al. Large-scale pattern growth of graphene films for stretchable transparent electrodes. Nature 457, 706-710 (2009).

12. Li, X. et al. Large-area synthesis of high-quality and uniform graphene films on copper foils. Science 324, 1312-1314 (2009).

13. Bae, S. et al. Roll-to-roll production of 30-inch graphene films for transparent electrodes. Nat. Nanotech. 5, 574-578 (2010).

14. Min, S. K., Kim, W. Y., Cho, Y. \& Kim, K. S. Fast DNA sequencing with a graphene-based nanochannel device. Nat. Nanotech. 6, 162-165 (2011).

15. Kim, W. Y. \& Kim, K. S. Prediction of very large values of magnetoresistance in a graphene nanoribbon device. Nat. Nanotech. 3, 408-412 (2008).

16. Singh, V. et al. Graphene based materials: past, present and future. Prog. Mater. Sci. 56, 1178-1271 (2011). 
17. Stevens, D. A., Hicks, M. T., Haugen, G. M. \& Dahn, J. R. Ex situ and in situ stability studies of PEMFC catalysts. J. Electrochem. Soc. 152, A2309-A2315 (2005).

18. Georgakilas, V. et al. Functionalization of graphene: covalent and non-covalent approaches, derivatives and applications. Chem. Rev. 112, 6156-6214 (2012).

19. Stankovich, S. et al. Graphene-based composite materials. Nature 442, 282-286 (2006).

20. Xu, Y. X., Wu, Q., Sun, Y. Q., Bai, H. \& Shi, G. Q. Three-dimensional selfassembly of graphene oxide and DNA into multifunctional hydrogels. ACS Nano 4, 7358-7362 (2010).

21. Mertig, M., Ciacchi, L. C., Seidel, R. \& Pompe, W. DNA as a selective metallization template. Nano Lett. 2, 841-844 (2002).

22. Stoltenberg, R. M. \& Woolley, A. T. DNA-templated nanowire fabrication. Biomed. Microdevices 6, 105-111 (2004).

23. Yi, H.-B., Lee, H. M. \& Kim, K. S. Interaction of benzene with transition metal cations: theoretical study of structures, energies, and IR spectra. J. Chem. Theory Comput. 5, 1709-1717 (2009).

24. Hong, B. H., Bae, S. C., Lee, C.-W., Jeong, S. \& Kim, K. S. Ultrathin singlecrystalline silver nanowire arrays formed in an ambient solution phase. Science 294, 348-351 (2001).

25. Hong, B. H. et al. Self-assembled arrays of organic nanotubes with infinitely long one-dimensional H-bond chains. J. Am. Chem. Soc. 123, 10748-10749 (2001).

26. Allen, M. J., Tung, V. C. \& Kaner, R. B. Honeycomb carbon: a review of graphene. Chem. Rev. 110, 132-145 (2010).

27. Erdem, A., Papakonstantinou, P. \& Murphy, H. Direct DNA hybridization at disposable graphite electrodes modified with carbon nanotubes. Anal. Chem. 78, 6656-6659 (2006)

28. Xu, C. Y., Zhang, P. X. \& Yan, L. Blue shift of Raman peak from coated $\mathrm{TiO}_{2}$ nanoparticles. J. Raman Spectrosc. 32, 862-865 (2001).

29. Tjoa, V., Jun, W., Dravid, V., Mhaisalkar, S. \& Mathews, N. Hybrid graphenemetal nanoparticle systems: electronic properties and gas interaction. J. Mater. Chem. 21, 15593-15599 (2011).

30. Stankovich, S. et al. Synthesis of graphene-based nanosheets via chemical reduction of exfoliated graphite oxide. Carbon 45, 1558-1565 (2007).

31. Park, S. \& Ruoff, R. S. Chemical methods for the production of graphenes Nat. Nanotech. 4, 217-224 (2009).

32. Lim, B. et al. Pd-Pt bimetallic nanodendrites with high activity for oxygen reduction. Science 324, 1302-1305 (2009).

33. Gasteiger, H. A., Marković, N., Ross, P. N. \& Cairns, E. J. Carbon monoxide electrooxidation on well-characterized platinum-ruthenium alloys. J. Phys. Chem. 98, 617-625 (1994)

34. Guo, J. W., Zhao, T. S., Prabhuram, J., Chen, R. \& Wong, C. W. Preparation and characterization of a $\mathrm{PtRu} / \mathrm{C}$ nanocatalyst for direct methanol fuel cells. Electrochim. Acta 51, 754-763 (2005).

35. Tiwari, J. N., Tiwari, R. N. \& Lin, K.-L. Synthesis of Pt nanopetals on highly ordered silicon nanocones for enhanced methanol electrooxidation activity. ACS Appl. Mater. Interfaces 2, 2231-2237 (2010).

36. Tiwari, J. N., Tiwari, R. N., Chang, Y.-M. \& Lin, K.-L. A Promising approach to the synthesis of $3 \mathrm{D}$ nanoporous graphitic carbon as a unique electrocatalyst support for methanol oxidation. Chem. Sus. Chem. 3, 460-466 (2010).

37. Tiwari, J. N., Pan, F.-M., Chen, T.-M., Tiwari, R. N. \& Lin, K.-L. Electrocatalytic activity of Pt nanoparticles electrodeposited on amorphous carbon-coated silicon nanocones. J. Power Sources 195, 729-735 (2010).

38. Tiwari, J. N., Pan, F.-M., Tiwari, R. N. \& Nandi, S. K. Facile synthesis of continuous Pt island networks and their electrochemical properties for methanol electrooxidation. Chem. Commun. 48, 6516-6518 (2008).
39. Liang, Y. et al. $\mathrm{Co}_{3} \mathrm{O}_{4}$ nanocrystals on graphene as a synergistic catalyst for oxygen reduction reaction. Nat. Mater. 10, 780-786 (2011).

40. Okamoto, Y. Density-functional calculations of icosahedral M13 (M $=\mathrm{Pt}$ and $\mathrm{Au})$ clusters on graphene sheets and flakes. Chem. Phys. Lett. 420, 382-386 (2006).

41. Youn, I. S. et al. Intercalation of transition metals into stacked benzene rings: a model study of the intercalcation of transition metals into bi-layered graphene. J. Chem. Theory Comput. 8, 99-105 (2012).

42. Kim, K. S., Tarakeshwar, P. \& Lee, J. Y. Molecular clusters of $\pi$-systems: theoretical studies of structures, spectra and origin of interaction energies. Chem. Rev. 100, 4145-4185 (2000).

43. Patil, A. J., Vickery, J. L., Scott, T. B. \& Mann, S. Aqueous stabilization and selfassembly of graphene sheets into layered bio-nanocomposites using DNA. Adv. Mater. 21, 3159-3164 (2009).

44. Myung, S. et al. Graphene-encapsulated nanoparticle-based biosensor for the detection of cancer biomarkers. Adv. Mater. 23, 2221-2225 (2011).

45. Myung, S. et al. Label-free polypeptide-based enzyme detection using a graphene-nanoparticle hybrid sensor. Adv. Mater. 24, 6081-6087 (2012).

46. Tanaka, S.-I., Miyazaki, J., Tiwari, D. K., Jin, T. \& Inouye, Y. Fluorescent platinum nanoclusters: synthesis, purification, characterization, and application to bioimaging. Angew. Chem. Int. Ed. 50, 431-435 (2011).

47. Wang, C., Li, J., Amatore, C., Chen, Y., Jiang, H. \& Wang, X. M. Gold nanoclusters and graphene nanocomposites for drug delivery and imaging of cancer cells. Angew. Chem. Int. Ed. 50, 11644-11648 (2011).

\section{Acknowledgements}

This work was supported by NRF (National Honor Scientist Program: 2010-0020414). N.H.L. was supported by SK Innovation Fellowship. Dr Nam-Suk Lee is gratefully acknowledged for measurement of High Resolution-TEM, which was performed at the National Center for Nanomaterials Technology at POSTECH, Korea.

\section{Author contributions}

J.N.T. designed and performed experiments. K.N. and S.K. prepared biological samples N.H.L. helped in synthesizing catalysts. D.H.Y., R.N.T. and J.S.L. discussed the interpretation of results. J.N.T., K.C.K. and K.S.K. wrote the manuscript. K.S.K. supervised the project.

\section{Additional information}

Supplementary Information accompanies this paper at http://www.nature.com/ naturecommunications

Competing financial interests: The authors declare no competing financial interests.

Reprints and permission information is available online at http://npg.nature.com/ reprintsandpermissions/

How to cite this article: Tiwari, J. N. et al. Stable platinum nanoclusters on genomic DNA-graphene oxide with a high oxygen reduction reaction activity. Nat. Commun. 4:2221 doi: 10.1038/ncomms3221 (2013).

(i) This work is licensed under a Creative Commons Attributionc. this license, visit http://creativecommons.org/licenses/by-nc-sa/3.0/ 